\title{
Aborto por anencefalia na mídia brasileira: análise retórica do debate entre as posições "pró-escolha" e "pró-vida"
}

O debate sobre a legalização e o caráter moral do aborto voluntário ou induzido frequentemente provoca reações diferentes e antagônicas, mobilizando as pessoas de forma passional, impondo posicionamentos adversos, nem sempre fundamentados por argumentos claros que sustentem, convincentemente, a adesão de uma posição favorável ou contrária a sua descriminalização/legalização. De forma emblemática, o debate se configura tendo de um lado os que se autodenominam "pró-vida", cujo nome designa a pretensão de seus membros. Do outro lado, encontra-se um grupo capaz de atrair inúmeras denominações, em geral, pejorativas, que dão ideia de um movimento orquestrado a serviço da morte, uma vez que, supostamente, advogam pela aniquilação do bem sagrado, que é a vida humana. Atribui-se a este grupo a alcunha de "abortistas", em detrimento das designações que lhe são próprias, como: "Pró-escolha", "Autodeterminação", "Pelo direto de decidir” (Domingues, 2008).

Colocando nesses termos, o debate revela um ardil ao propor a discussão a partir da polarização em torno do direito à vida como se a defesa desse direito fosse prerrogativa de apenas um dos pólos ativos da questão, além de minimizar, ou mesmo excluir, a incidência de qualquer outro elemento capaz de intervir na compreensão do tema, ampliando-a (Domingues, 2008).

Estima-se que 68.000 mulheres morrem, por ano, em todo o mundo, em decorrência do aborto inseguro, ou seja, oito mulheres por hora. Esses números levam à estimativa de uma razão de mortalidade de 367 mortes por 
100.000 abortos inseguros, o que é infinitamente superior à taxa de mortalidade causada pelo abortamento seguro, que é menor que uma morte por cada 100.000 procedimentos (OMS, 2004). A razão de morte por abortamento seguro é até menor do que a razão de morte materna. Ou seja, interromper uma gravidez utilizando métodos seguros é mais seguro do que levar uma gravidez, mesmo que normal e sem complicações, adiante. Dessa forma, o abortamento inseguro deveria ser entendido como um problema de saúde pública (Santiago, 2008).

O abortamento inseguro ocorre no mundo inteiro, mas tem uma distribuição irregular, e de acordo com fatores sociais e permissivos legais. Os dados mostram que $97 \%$ de todos os abortos inseguros são realizados em países em desenvolvimento e apenas 3\% em países desenvolvidos (OMS, 2004). No Brasil, há diversas estimativas acerca do número de abortos induzidos. Os dados que nos permitem uma aproximação com a realidade são os relativos à internação de mulheres em hospitais públicos para a realização de curetagem pós-aborto - o que exclui mulheres sem nenhum acesso ao sistema público de saúde e mulheres usuárias de saúde suplementar. $\mathrm{O}$ número de mulheres que se tratou, em hospitais públicos, por complicações relacionadas ao aborto diminuiu nas estatísticas oficiais. Ainda assim, está longe de ser razoável: de 345.000 mulheres internadas, em 1992, para 250.000, em 2005; uma diminuição de $28 \%$. A maior queda, no entanto, aconteceu no ano de 1995 e, posteriormente, a redução tem sido insignificante (Santiago, 2008).

\section{Anencefalia no Supremo Tribunal Federal}

Segundo Diniz e Vélez (2008, p. 648):

anencefalia é um distúrbio de fechamento do tubo neural diagnosticável nas primeiras semanas de gestação. Por diversas razões, o tubo neural do feto não se fecha, deixando o cérebro exposto. O líquido amniótico gradativamente dissolve a massa encefálica, impedindo o desenvolvimento dos hemisférios cerebrais. Não há tratamento, cura ou qualquer possibilidade de sobrevida de um feto com anencefalia. Em mais da metade dos casos, os fetos não resistem à gestação, e os poucos que alcançam o momento do parto sobrevivem minutos ou horas fora do útero.

Durante o mês de abril de 2004, uma liminar foi concedida pelo ministro Marco Aurélio de Mello à Arguição de Descumprimento de Preceito Fun- 
damental (ADPF) proposta pela Confederação Nacional dos Trabalhadores na Saúde com assessoria da Anis: Instituto de Bioética, Direitos Humanos e Gênero (Barroso 2005, apud Diniz e Velez, 2008).

Sobre a ADPF como instrumento jurídico, Diniz e Vélez (2008, p. 648) afirmam que:

é um instrumento jurídico ainda pouco utilizado na jurisprudência brasileira, pois permite que a sociedade civil interpele diretamente a Suprema Corte. A liminar que autorizava a interrupção da gestação em caso de anencefalia no feto foi cassada na sessão plenária do Supremo Tribunal Federal (STF), em 20 de outubro de 2004. Após quatro meses em vigência, a liminar foi derrubada por ter sido considerado necessário o julgamento prévio do instrumento jurídico utilizado para a apresentação da ação. A ADPF 54 foi tema de diversas audiências e atualmente está prevista para entrar na pauta do Supremo a qualquer momento. A ADPF é um instrumento jurídico novo e pouco utilizado no país, e, segundo alguns dos juízes, era preciso primeiro um julgamento sobre a sua validade antes da concessão da liminar. Em 28 de abril de 2005, os juízes deliberaram pelo cabimento do instrumento, e o mérito da ação ainda está por ser julgado. Indiferente aos argumentos processuais que justificariam ou não a cassação da liminar, o cerne da sessão plenária foi uma extensa discussão metafísica sobre o início e o sentido da vida humana, um tema provocativo e ameaçador para as fronteiras da razão pública em um Estado laico.

Segundo Barroso (2004, apud Diniz e Vélez 2008), o argumento jurídico e ético proposto na ação era de que, por ser a anencefalia uma malformação inconciliável com a sobrevivência do feto para além do útero materno, a interrupção da gestação neste caso não deveria ser tipificada como crime, mas como um procedimento médico amparado em princípios constitucionais como o direito à saúde, à dignidade, à liberdade e a estar livre de tortura.

Para Diniz e Vélez (2008, p. 648):

estratégia argumentativa da ação foi a de demonstrar que outros princípios constitucionais devem fazer parte do debate público e político sobre o aborto. A anencefalia foi um recurso metodológico para a imposição de uma nova argumentação, ao permitir suplantar a retórica cristã tradicional do aborto como um atentado a uma vida humana em potencial. 


\section{Enquadre conceitual e teórico}

A retórica é considerada, neste artigo, como um aspecto da relação antagônica entre versões: como se contrapõe uma descrição a outra descrição alternativa e/ou contrária, e como ela se organiza, ao mesmo tempo, para resistir a uma oposição (Billig, 1991). Ou seja, a retórica é o modo como argumentos opostos se enfrentam numa controvérsia. Para a análise retórica da controvérsia sobre a moralidade do aborto de fetos anencefálicos nos apoiaremos nas categorias analíticas: gêneros retóricos e recursos estratégicos, díxis e repertórios interpretativos.

\section{Gêneros retóricos}

Os teóricos da retórica identificaram três gêneros persuasivos ou retóricos: o forense, o deliberativo e o epidêitico (Gross, 1990; Fahnestock, 1986 apud Leach, 2002), categorizados a partir do objetivo, do público, da situação e do tempo. A retórica forense é própria dos tribunais, em que a discussão se centra na natureza e na causa de acontecimentos passados e os interlocutores devem persuadir um terceiro grupo de que sua explicação dos acontecimentos passados é uma explicação "verdadeira”. A retórica deliberativa é encontrada na arena política, na qual o debate se centra no melhor rumo possível de uma ação futura. Esta forma de persuasão é, portanto, orientada para o futuro e muitas vezes especulativa. A retórica epidêitica está centrada em temas contemporâneos e na avaliação se determinado indivíduo ou acontecimento merecem louvor, são culpados ou devem ser censurados. As formas clássicas de retórica epidêitica são orações fúnebres e cerimônias de premiação.

\section{Recursos estratégicos}

Segundo Potter (1996), as pessoas utilizam estratégias argumentativas para produzir relatos que atendam a seus interesses, sem serem consideradas explicitamente como interessadas. O dilema de manejar sentidos em favor de interesses, sem que se deixe evidente as estratégias de manipulação, pode ser articulado de diferentes formas por meio dos relatos. Ou seja, as pessoas podem desempenhar ações atributivas, tais como culpar indiretamente ou implicitamente, se desculpar ou recusar convites, pela produção de um relato factual e ostensivamente desinteressado. Para o estudo desses relatos, Potter propõe a análise de recursos estratégicos, são eles: 
a) Direito Categorial: no qual a veracidade de um relato particular será garantida pelo direito de membro da categoria do falante, ou seja, espera-se que pessoas em categorias particulares - oficiais ou não - tenham conhecimento de certas coisas ou tenham certos esquemas epistemológicos.

b) Descrição Vívida: rica em detalhes contextuais e incidentes. Pode ser usada para criar uma impressão de experiência perceptual, assim como indicar que o falante ou escritor tem um esquema particular de observação.

c) Narrativa: um relato pode ter sua veracidade aumentada por fixá-lo numa sequência narrativa particular na qual o evento é esperado ou mesmo necessário.

d) Imprecisão Sistemática: é a retórica contrária da descrição vívida e da narrativa. Fundamenta-se no fato de que a riqueza de detalhes pode garantir a veracidade do relato, como também pode proporcionar elementos para uma contestação.

e) Relatos Empiricistas: característica das falas e escritos científicos. Trata o fenômeno como agente e apaga o observador inteiramente ou o trata como um recipiente passivo. Neste discurso, os fatos impõem-se aos atores humanos, que têm um papel inteiramente secundário, no qual o observador recolhe a informação que o meio oferece.

f) Retórica de Argumento: constrói afirmações de lógica, silogística ou outro tipo de argumento bem conhecido que fornece um meio de torná-los externos ao falante ou escritor. Esquemas deste tipo são particularmente importantes quando versões estão sendo mobilizadas para proporcionar inferências atributivas particulares, como, por exemplo, de culpa, por apresentá-las como requeridas pelos eventos ou ações em si mesmas, mais do que desejadas pelo falante.

g) Formulações de casos extremos: esta estratégia foi explorada por Pomerantz (1986 apud Potter, 1996), que observou como se pode tornar um relato mais efetivo ao direcioná-lo aos extremos de dimensões relevantes de julgamento.

h) Consensos e Confirmação: uma maneira de garantir a factualidade de uma versão é descrevê-la de acordo com testemunhas ou como confirmada por observadores independentes. Às vezes, o consenso combina com a normatividade, o que combina aquilo que é próprio da categoria (norma) com aqueles que concordariam com tal categoria (consensos); podendo ser agrupado numa formulação de caso extremo. 
i) Listas e Contrastes: oratórias políticas atestam para a efetividade retórica dessas estratégias. A lista é combinada com um contraste que formula a versão factual em oposição a uma alternativa ameaçadora, que é formulada de uma maneira problemática ou pouco convincente.

\section{Díxis}

A pesquisa na perspectiva da linguagem em uso implica focalizar as maneiras pelas quais as pessoas produzem sentidos e posicionam-se em relações sociais cotidianas. A linguagem em uso é o que define a Pragmática, uma das correntes teórico-metodológicas que deram origem à análise de discurso. Não é possível se comunicar sem dispor de uma ancoragem linguística nos contextos físicos, relacionais e sociais e essa operação linguística tem que ser decodificada, porque, se não se produz essa decodificação, a compreensão é impossível.

A Pragmática, juntamente com o "giro linguístico", Teoria dos Atos da Fala, Etnometodologia e alguns aspectos da obra de Michel Foucault, são eixos que fundamentam a análise de discurso que elegemos para esta pesquisa. A Pragmática nos é útil por oferecer o arsenal teórico e metodológico para a análise da linguagem em uso (Iñiguez, 2004).

É da Pragmática que trazemos o termo díxis, para nos referirmos àqueles elementos da estrutura gramatical que relacionam a linguagem com o contexto, o que para nós é fundamental para entender o contexto agonístico (Billig, 1991) em que se travam as controvérsias. Os dícticos codificam as relações da linguagem e o contexto da enunciação, e o fazem cumprindo diversas funções, tais como assinalar ou indicar lugares e/ou coisas, pessoas, momentos, etc. De acordo com Levinson:

O termo díxis se origina da palavra grega para assinalar ou indicar, sendo exemplos prototípicos ou principais o uso dos demonstrativos, os pronomes de primeira e segunda pessoa, o tempo verbal, advérbios específicos de tempo e lugar como "agora" e "aqui", e vários outros aspectos gramaticais ligados diretamente às circunstâncias da enunciação (Levinson, 1983, p. 47 apud Iñiguez, 2004, p. 66).

Os dícticos podem ser de cinco tipos (Iñiguez, 2004):

a) pessoal, quando se referem a pessoas e indicam o papel que cada um desempenha na interação: "eu”, "nós”, "eles", assim como vocativos tais como "tio/tia” ou "macho", são exemplos de dícticos de pessoa; 
b) de lugar, quando se referem a lugares, localizando as pessoas ou objetos aos quais se referem na conversação. Por exemplo, "aqui", "ali", "adiante".

c) de tempo, quando se referem aos vários momentos daquilo que se está narrando, tomando como ponto de referência o momento em que se dá a conversação. Por exemplo: "mais tarde", "daqui a pouco".

d) do discurso, que se refere à referência a outras partes do discurso, anteriores ou posteriores. Por exemplo, "como vimos no Capítulo 1". Expressões como "definitivamente", "portanto", "no entanto" e outras semelhantes também têm essa função díctica discursiva. Quando os dícticos de discurso constituem referência a autoridades, enunciados ou textos que visam legitimar um determinado argumento, podemos considerar que eles se caracterizam como argumentos de autoridade, conforme já discutido.

e) Social, que se refere à codificação das distinções sociais dos papéis dos participantes na conversação, em particular, quando indicam a relação social entre os participantes. São exemplos de dícticos sociais as fórmulas de tratamento "tu", "você", ou "o/a senhor/a".

\section{Repertórios interpretativos}

Um dos aspectos centrais da Psicologia Discursiva é a noção de repertórios interpretativos - conjunto de termos, lugares comuns e descrições utilizadas em construções gramaticais e estilísticas. Constituem os dispositivos lingüísticos que utilizamos para construir versões dos eventos, ações e outros fenômenos que estão a nossa volta, presentes em uma variedade de produções linguísticas e que atuam como substrato para uma argumentação (Potter e Wetherell, 1987).

Os repertórios interpretativos demarcam o plano de possibilidades de construções discursivas; são aprendidos e construídos ao longo de nossa vida, em diferentes momentos e contextos. Dessa forma, por meio dos repertórios podemos entender tanto a permanência como a dinâmica e a variabilidade das produções linguísticas.

De forma geral, ao identificarmos repertórios em textos ou falas, podemos compreender alguns sentidos - consensuais e contraditórios - que circulam no cotidiano e que podem assumir outras significações no esforço de produção de sentido empreendido por um leitor ou interlocutor. Isto significa que os textos, como prática discursiva, ampliam a gama de repertórios disponíveis às pessoas, possibilitando a produção de outros sentidos e a construção de 
versões diversas sobre si e o mundo a sua volta. Os repertórios são colocados em movimento nos processos de interanimação dialógica, inseridos num contínuo processo de negociação, desenvolvido a partir de trocas comunicativas, num espaço de interpessoalidade, e compõem as unidades básicas da linguagem e as da comunicação (Spink, 2000).

Em síntese, os repertórios interpretativos são os termos, os conceitos, os lugares-comuns, as figuras de linguagem e de retórica que demarcam o rol de possibilidades de construção de sentidos. Esses repertórios circulam na sociedade de formas variadas. Aprendemos repertórios no próprio processo de aprendizagem da linguagem, por meio de livros, dos filmes que assistimos, das conversas cotidianas e demais meios de comunicação.

\section{Procedimentos de pesquisa}

O corpus de documentos da mídia escolhidos para a análise retórica desta pesquisa foi composto por matérias jornalísticas produzidas pelos atores sociais de posições distintas e contrárias na controvérsia moral sobre a autorização legal do aborto em casos de anencefalia do feto.

De um lado, a entrevista concedida por Débora Diniz à Revista Época, em 2004, e o artigo "Anencefalia: dois anos de espera", escrito pela feminista em 2006 e publicado no site da Assessoria de Comunicação (ACS) da Universidade de Brasília (UnB), foram as matérias escolhidas para análise da posição "pró-escolha". De outro lado, os artigos "Aborto e democracia", publicado em 2004, e "Brasileiro é contra o aborto", de 2006, ambos de autoria de Carlos Alberto Di Franco, foram eleitos para a análise da defesa dos argumentos "pró-vida". A definição desses documentos se deu como estratégia para contemplar momentos distintos de produção de sentidos sobre a argumentação defendida por Débora Diniz e Carlos Alberto Di Franco a respeito da autorização da liminar do Ministro Marco Aurélio Mello.

Tivemos acesso à entrevista de Débora Diniz, publicada na Revista Época, por meio do site da própria Revista ${ }^{1}$. A escolha por essa matéria jornalística se deu com a ajuda das informações fornecidas pelo estudo de Sanematsu (2005), que indicou esta entrevista como uma das principais produções da feminista acerca do tema. A outra matéria relacionada à produção de Débora Diniz sobre seus posicionamentos acerca da defesa moral do direito de livre

Disponível em http://revistaepoca.globo.com/Epoca/0,6993,EPT757558-1666-1,00.html. 
escolha pelo aborto, o artigo "Anencefalia: dois anos de espera" foi localizada a partir de seu Currículo Lattes, disponível no site do Conselho Nacional de Desenvolvimento Científico e Tecnológico $(\mathrm{CNPq})^{2}$. A busca pelo segundo artigo se deu com o objetivo de localizar uma produção retórica da autora após a cassação da liminar. Por meio do Currículo Lattes de Débora Diniz, chegamos ao site onde esse artigo $^{3}$ foi publicado e adquirimos o documento.

Os artigos de Carlos Alberto Di Franco também foram escolhidos a partir das informações oferecidas pelo estudo de Sanematsu (2005), e foram adquiridos no site do jornal O Estado de S. Paulo ${ }^{4}$, onde foram publicados. O primeiro artigo, "Aborto e democracia", foi destacado pela pesquisadora, e o segundo, "Brasileiro é contra o aborto", foi obtido a partir de uma busca no referido site.

A análise desses quatro documentos midiáticos é apresentada a seguir e foi realizada seguindo os seguintes passos: descrição do contexto de produção e do conteúdo argumentativo de cada uma das matérias; análise dos dícticos, composta pela identificação e descrição dos tipos de dícticos e suas finalidades, exceto no artigo publicado em 2006 de Di Franco: "Brasileiro é contra o aborto", pois os usos se repetiam em relação ao artigo de 2004; análise dos dícticos como argumento de autoridade, realizada apenas nos artigos assinados por Di Franco, pois na entrevista e no artigo de Débora Diniz não identificamos o uso da estratégia de empilhamento de argumentos de autoridade; análise dos repertórios interpretativos, que consistiu na interpretação dos usos dos termos associados à interrupção da gestação, gestante e concepto (ou embrião) empregada em cada uma das quatro matérias; análise retórica, que consistiu na interpretação da utilização dos recursos estratégicos usados nos quatro documentos midiáticos.

\section{Débora Diniz: porta-voz da posição “pró-escolha”}

A entrevista concedida por Débora Diniz à Revista Época, em 2004 - ano de publicação da liminar -, e o artigo "Anencefalia: dois anos de espera", publicado em 2006 - dois anos após a cassação da liminar -, são os dois documentos midiáticos analisados para descrever a retórica de defesa da posição "pró-escolha”.

Disponível em http://buscatextual.cnpq.br/buscatextual/index.jsp.

Disponível em http://www.secom.unb.br/artigos/at1006-06.htm

Disponível em http://txt.estado.com.br/editorias/2007/10/22/opi-1.93.29.20071022.3.1.xml 


\section{A entrevista à Revista Época}

Em entrevista de três páginas, publicada em julho de 2004 na Revista Época, sob o título "Em nome da mãe", a antropóloga Débora Diniz, da Universidade de Brasília, foi apresentada como "a principal articuladora da ação que colocou o aborto na pauta de discussão nacional”. A matéria, assinada pela jornalista Eliane Brum, foi organizada em três partes: a primeira é uma narrativa contextual sobre o momento em que Débora Diniz concedeu a entrevista; a segunda é uma apresentação da biografia da entrevistada, com informações sobre sua vida pessoal, trajetória acadêmica e atuação profissional; e a terceira é a entrevista, propriamente dita.

A retórica epidêitica, centrada no tema em pauta no momento da publicação da entrevista, a liminar do ministro Marco Aurélio Mello, foi caracterizada pela argumentação de avaliação positiva a respeito da concessão da autorização da "antecipação terapêutica do parto" em casos de anencefalia do feto. A linguagem coloquial, próxima aos usos linguísticos cotidianos das pessoas, foi uma característica do gênero epidêitico usado por Débora Diniz. Os endereçamentos do seu discurso foram construídos de acordo com as perguntas que a jornalista lhe fazia, e a intertextualidade foi marcada por narrativas e descrições de eventos que Débora Diniz relatou durante a entrevista.

\section{Sobre os usos dos dícticos na entrevista à Revista Época}

Com o objetivo de descrever o contexto agonístico (Billig, 1991) de produção da entrevista concedida por Débora Diniz à Revista Época, elaboramos, conforme o modelo de análise dos documentos jurídicos, apresentados no capítulo anterior, um quadro que buscou identificar os dícticos utilizados na entrevista. Esta estratégia permitiu a visualização dos lugares/espaços, das pessoas/instituições e das posições dos atores sociais implicados nas enunciações da controvérsia defendidas por Débora Diniz.

Os dícticos de discurso foram usados na entrevista com a finalidade de enunciar a articulação política de Débora Diniz junto à CNTS, autora da ADPF-54; anunciar os protestos contra a demissão de Débora Diniz da Universidade Católica de Brasília; enunciar o tema da anencefalia do feto; narrar o enfrentamento do dilema entre anencefalia e deficiência em um programa coordenado por pesquisadoras deficientes ou que eram cuidadoras de deficientes; comentar e se opor aos argumentos da CNBB que igualou 
anencéfalos a deficientes; situar e diferenciar a anencefalia da luta política dos deficientes; enunciar a ausência de possibilidade de um anencéfalo pleitear o seu direito de estar no mundo; concluir a argumentação que a liminar seria uma vitória feminista; adjetivar e qualificar o advogado da CNTS, Luís Roberto Barroso; indicar que apenas a Igreja Católica e as feministas falam em aborto; anunciar a conclusão do argumento que a antecipação terapêutica do parto não seria aborto e enunciar, historicamente, que foi a primeira vez que o STF assumiu que direitos reprodutivos dizem respeito aos preceitos constitucionais da liberdade, da dignidade e do direito à saúde.

Os dícticos de tempo foram usados para indicar o contexto temporal de realização da entrevista; informar o momento em que Débora Diniz superou o temor de que a interrupção da gestação por anencefalia prejudicasse os deficientes e mencionar a importância das imagens de anencéfalos para se compreender a anomalia.

Os dícticos de lugar foram utilizados com a finalidade de indicar o local onde foi realizada a entrevista; para referir-se à decisão de autorizar, por liminar, a antecipação terapêutica do parto; questionar se a liminar significaria a liberalização do aborto no país; indicar a repercussão da notícia da liminar; mencionar os locais onde Débora Diniz sofreu perseguição política; apresentar o lugar onde ela enfrentou o dilema entre anencefalia e deficiência; situar a conversa que a entrevistada teve com a teórica que a ajudou no enfrentamento desse dilema; enunciar o embate político acerca da anencefalia dentro do próprio movimento feminista; situar a controvérsia sobre a moralidade do aborto no campo do conflito moral (e não do dilema moral) e argumentar em defesa da pluralidade moral. Os dícticos pessoais foram usados para indicar o papel que a ANIS desempenhou na articulação política pela autorização da antecipação terapêutica do parto e anunciar a oposição aos que defendem a imoralidade da antecipação terapêutica do parto.

Sobre os usos dos repertórios interpretativos na entrevista à Revista Época

A análise discursiva do uso dos repertórios interpretativos objetivou identificar as nomeações, definições, conjunto de termos e expressões utilizadas na entrevista. Como afirmamos na seção anterior, o uso de determinados termos indica a premissa moral que sustenta a argumentação dos atores em controvérsia e a análise desses termos permite-nos identificar quais 
são as posições morais em conflito agonístico. Os repertórios associados à nomeação da interrupção da gestação, os termos usados para nomeação da gestante e as nomeações do concepto ou embrião, são os que nos interessam para conhecer os pressupostos morais em conflito na controvérsia sobre os sentidos da vida acerca do aborto induzido, considerando o contexto retórico de utilização das respectivas nomeações. O quadro a seguir sistematiza os usos dos repertórios de nomeações para interrupção da gestação, gestante e concepto, na matéria jornalística da Revista Época, que publicou a entrevista concedida por Débora Diniz.

A expressão "mulher" foi associada ao termo "gestante" para designar a portadora do embrião e, ao longo de toda a entrevista, Débora Diniz não fez referência a nenhuma outra forma de nomear a gestante. O uso restrito e reiterado do termo "mulher" posicionou moralmente a premissa de defesa da vida da gestante e do seu direito de decidir pela interrupção da gestação. Relacionados a esse uso encontramos os termos "aborto" e "feto", utilizados para compor o sentido de sobreposição do direito de escolha da gestante sobre o suposto direito à vida do embrião. Embora Débora Diniz argumentasse em defesa da pluralidade moral, a organização retórica dos repertórios valoriza a defesa da vida e do livre exercício dos direitos reprodutivos da mulher:

Essa questão surgiu da vida real, das mulheres que se viam duplamente torturadas: pela gravidez e pela polêmica do aborto. O debate polarizado, de um lado a ideia de que o corpo pertence às mulheres, das feministas, e de outro o direito potencial à vida do feto, da Igreja, é interminável porque são posições de fé. A anencefalia do feto é exemplar para colocar em xeque os limites dessa argumentação.

A expressão “interrupção da gestação” também foi usada por Débora Diniz para compor o repertório associado ao "aborto": "Eu temia que a interrupção da gestação por anencefalia pudesse ser prejudicial para os deficientes”.

O termo "aborto", combinado com a composição "não é aborto", organizou a argumentação persuasiva que buscou fundamentar a não caracterização do crime de aborto nos casos de anencefalia do feto. Como no trecho a seguir:

Só a Igreja e as feministas falam em aborto. As mulheres pobres falam em "tirar". Elas diziam: "Eu não quero abortar, só quero tirar". Explicavam que queriam acabar logo 
com o sofrimento. A legislação brasileira proíbe o aborto porque supõe ser um crime contra a vida. $\mathrm{Na}$ anencefalia não há sequer expectativa de vida. Então não é aborto.

"Antecipar o parto" foi uma construção gramatical usada na retórica de Débora Diniz para imprimir à interrupção da gestação o caráter de legalidade. A organização retórica desse uso visou generalizar o emprego do termo "antecipação terapêutica do parto" para outros casos de aborto induzido ou voluntário, numa estratégia argumentativa epidêitica que usou o termo, aplicado para uma situação específica e atípica juridicamente - a anencefalia -, ampliando seu empregou para os demais casos, que têm tratamento legal cristalizado pelo Estado:

Sem dúvida. O que é muito importante é que nenhuma mulher vai ser obrigada a antecipar o parto [...]. Agora, há outras mulheres que acham o contrário. Nem as feministas podem defender que uma mulher tem de abortar, nem um religioso dizer que não. Uma legislação que despenalize o aborto não significa nenhuma ofensa àqueles que acreditam que o aborto é imoral, porque não significa obrigatoriedade.

Os termos "mulher" e "aborto" ainda foram usados na retórica de Débora Diniz para situar sua posição de defesa da pluralidade moral: "Nem as feministas podem defender que a mulher tem de abortar, nem um religioso pode dizer que não".

Sobre os usos da retórica na entrevista à Revista Época

A análise retórica da entrevista concedida por Débora Diniz à Revista Época se centrou na interpretação dos recursos estratégicos: descrição vívida, narrativa, imprecisão sistemática e retórica de argumento.

\section{Descrição vívida}

O recurso estratégico descrição vívida compôs a retórica de Débora Diniz para organizar o discurso de convencimento acerca da distinção entre a defesa do direito ao aborto, nos casos de anencefalia do feto, e a luta pela cidadania dos deficientes físicos. A descrição rica em detalhes contextuais e incidentes foi usada para criar a impressão de que a entrevistada possuía uma percepção diferenciada e privilegiada por ter vivido determinadas experiências emocionais. $\mathrm{O}$ trecho a seguir ilustra esse uso retórico: 
Eu temia que a interrupção da gestação por anencefalia pudesse ser prejudicial para os deficientes. Só fui solucionar esse dilema em 2001, quando participei de um programa nos EUA sobre os desafios da deficiência e da Justiça. Esse programa era coordenado por duas grandes teóricas americanas. Uma delas era Anita Silvers, filósofa e deficiente física. A outra, Eva Kittay, filósofa, cuidava de uma filha com paralisia cerebral grave. A minha apresentação era a penúltima e eu não sabia como fazê-la. Anita percebeu minha tensão e fomos conversar à beira de um lago, em Nova York. Falei que eu estava com medo de que repercutisse nos deficientes. Ela disse: "Você não está falando de mim em seu debate, está falando de alguém que não está entre nós. Olhe ao redor, não há pessoas anencéfalas no mundo. É um desrespeito à comunidade deficiente nos comparar aos anencéfalos".

\section{Narrativa}

A narrativa foi o recurso estratégico usado pela jornalista que entrevistou Débora Diniz para introduzir o conteúdo da matéria. A estratégia retórica consistiu em apresentar uma série de acontecimentos, organizados em sequência narrativa. Esse recurso foi combinado com a descrição vívida numa organização retórica que construiu a descrição do fato como verídico, com o objetivo de sustentar a afirmação de que a entrevistada foi a principal articuladora política da ação da CNTS, que desembocou na liminar do Ministro Marco Aurélio Mello:

Na terça-feira, quando Débora Diniz dava esta entrevista a ÉPOCA num restaurante de Brasília, foi interrompida por um telefonema. Era Richard Reiter, secretário para Assuntos Políticos da embaixada americana. Ele queria saber quem era ela, quais eram suas motivações e se a decisão do Supremo de autorizar, por liminar, a interrupção da gestação no caso de anencéfalos (fetos sem cérebro) poderia significar a liberalização do aborto no Brasil. Reiter disse que a notícia repercutiu nos Estados Unidos e precisava abastecer o governo Bush de informações.

A narrativa também foi usada pela entrevistada para atrelar à sua retórica de argumentos relatos factuais que pudessem atestar a veracidade do seu relato em defesa da estratégia política que coloca o caso da anencefalia como questão central no debate acerca do aborto. Como adepta de um pluralismo de valores morais, Débora Diniz organizou sua argumentação para fazer notar que qualquer valor moral levado ao limite conduz à incompatibilidade com outros valores morais. 
Numa das reuniões em que defendíamos o ponto de vista da anencefalia, uma feminista importante me disse que eu fazia parte da geração do medo. E que elas eram da geração da coragem. Esse foi um embate em minha própria comunidade. Crescemos juntas e hoje as feministas estão unidas em torno do Supremo. Ou reconhecemos que as crenças das pessoas são importantes e as levamos a sério ou saímos perdendo. $\mathrm{Na}$ lógica desse processo está a necessidade de reconhecer no outro alguma possibilidade de encontro de horizontes. Ou quem ganha o embate é a força. E eles sempre são mais fortes que nós.

\section{Imprecisão sistemática}

O relato vago foi estratégia usada por Débora Diniz para atestar a fundamentação empírica, que ela fez parecer ter extraído das suas próprias experiências, para sustentar a defesa de que "antecipação terapêutica do parto" não é aborto.

Só a Igreja e as feministas falam em aborto. As mulheres pobres falam em "tirar". Elas diziam: "Eu não quero abortar, só quero tirar". Explicavam que queriam acabar logo com o sofrimento. A legislação brasileira proíbe o aborto porque supõe ser um crime contra a vida. Na anencefalia não há sequer expectativa de vida. Então não é aborto.

\section{Retórica de argumento}

A organização retórica de Débora Diniz forneceu um sentido reiterado de coisificação do discurso que visou solapar as afirmações opostas às suas, dos seus dissidentes, adjetivando-as. A força persuasiva do seu argumento tornou-se evidente com as construções de afirmações lógicas, organizadas de forma a parecer irrefutável. Como no trecho a seguir:

Não sei que fiéis a CNBB acha que está representando quando fala isso, mas tenho certeza de que não fala pela massa de católicos. É uma posição fundamentalista, de quem não consegue repensar seus dogmas. Quando dizem que anencéfalos são deficientes, estão fazendo um desserviço. O centro da luta dos deficientes é o direito à cidadania. $\mathrm{Na}$ anencefalia estamos falando de alguma coisa que jamais vai chegar a ser alguém, portanto nunca vai poder pleitear o seu direito de estar no mundo. Então, por que torturar espiritualmente essas mulheres dizendo que isso é pecado?

A defesa do uso do termo "antecipação terapêutica do parto", para referir-se à interrupção da gestação nos casos de anencefalia do feto, foi 
feita assumindo a estratégia política implícita na proposta de substituição do termo aborto:

É uma definição que consegue escapar da guerrilha do aborto. Consegue fazer com que as pessoas escutem o que temos a dizer. O grande desafio do aborto é tirar o debate do dilema moral, em que só existe a possibilidade do "sim" e do "não", e passá-lo para o campo do conflito moral, no qual as possibilidades são muitas. Pode ser sim aqui, não ali, talvez.

A retórica em defesa de um Estado Laico foi organizada de modo a fazer crer ser possível a convivência pacífica entre inimigos morais, desde que fossem respeitadas as diferenças de crença:

Uma legislação que despenalize o aborto não significa nenhuma ofensa àqueles que acreditam que o aborto é imoral, porque não significa obrigatoriedade. O problema é que a característica das comunidades morais é o espírito missionário. Ou seja: não basta acreditar, tem de fazer com que os outros acreditem. Cada um tem o direito de acreditar no que quer. E as leis, num Estado laico, têm de garantir essa pluralidade.

O discurso ironizador compôs a organização argumentativa da entrevistada, e teve como objetivo solapar as concepções morais que consideram a existência de vida humana a ser protegida desde a fecundação, defendendo a veiculação de fotos e imagens de fetos anencefálicos como estratégia para desconstruir a noção de que seria possível ter vida a ser valorizada nesses casos:

Toda a argumentação de resistência ao aborto é a tentativa de aproximar um conjunto de células da humanidade. As imagens acabam com os argumentos contrários à interrupção da gestação. Elas descortinam um mundo proibido dentro do ideal da maternidade. Mostrar as fotos era dizer que isso faz parte do mundo e precisamos ser solidários com essas mulheres.

\section{O artigo "Anencefalia: dois anos de espera"}

Dois anos após a concessão, e posterior cassação, da liminar do Ministro Marco Aurélio Mello, Débora Diniz publicou um artigo jornalístico, intitulado "Anencefalia: dois anos de espera" no site da Assessoria de Comunicação (ACS) da Universidade de Brasília (UnB), em outubro de 2006, onde ela retomou o tema do julgamento da liminar. 
$\mathrm{O}$ artigo tem duas páginas, e a autora utilizou uma linguagem coloquial, semelhante aos usos linguísticos e gramaticais feitos pelos jornalistas. A linguagem jurídica também compôs o conteúdo do texto: "O Supremo Tribunal Federal é o espaço legítimo e mais representativo da argumentação razoável em uma democracia laica constitucional como é o Brasil”. A retórica epidêitica foi caracterizada pela narrativa de casos contemporâneos de gestação de anencéfalos, com detalhes do caso da gestante Severina, que estava internada para realizar a interrupção da gestação quando a liminar foi cassada e a impediu de realizar o procedimento, pela avaliação da consequência de não ter sido votado, em definitivo, o pedido de autorização do aborto de fetos anencefálicos, desde 2004.

Sobre os usos dos dícticos no artigo "Anencefalia: dois anos de espera"

A análise dos dícticos do artigo de Débora Diniz deu-se da mesma forma que a análise dos dícticos da entrevista, apresentada anteriormente.

Os dícticos de tempo foram utilizados na retórica do artigo de Débora Diniz para mencionar o tema do aborto voluntário como decisivo nos processos eleitorais brasileiros; enunciar o tempo decorrido desde a cassação da liminar; indicar o tempo que vigorou a liminar do Ministro Marco Aurélio; anunciar a data de cassação da liminar; indicar a narrativa do caso de Severina; comunicar o tempo em que esta gestante procurou ajuda judicial para realizar a interrupção da gestação; enunciar que, atualmente, com a cassação da liminar, as gestantes são impedidas de abortar; anunciar que a resposta definitiva sobre a gestação de anencéfalos não foi dada pelo STF.

O uso dos dícticos de lugar teve por finalidade situar um exemplo onde a posição em defesa da legalização do aborto reverteu o resultado das eleições; situar a ação sobre o aborto de fetos anencefálicos; enunciar o lugar onde estão registradas e narradas as histórias de gestantes de fetos anencefálicos; situar o local onde a gestante Severina esteve internada para fazer o aborto e foi impedida; enunciar os locais onde esta gestante tentou reverter a decisão que a impediu de abortar, tentando uma autorização judicial. Os dícticos de discurso foram utilizados para indicar a instância governamental que reconheceu, durante a vigência da liminar, o direito da gestante de anencéfalo abortar. 
Sobre os usos dos repertórios interpretativos no artigo "Anencefalia: dois anos de espera"

A análise dos repertórios interpretativos no artigo de Débora Diniz teve os mesmo objetivos e foi realizado do mesmo modo que a análise dos demais documentos que compõem o material empírico desta pesquisa. O quadro a seguir mostra a sistematização dos usos retóricos para nomear a interrupção da gestação, a gestante e o feto, no texto do artigo.

Novamente, como aconteceu com a entrevista concedida por Débora Diniz à Revista Época, o único repertório usado para nomear a gestante foi "mulher", marcando a posição moral de defesa da premissa do direito à livre escolha pelo aborto. A expressão "feto" foi usada no repertório associado ao embrião, relacionado ao termo "mulher" para contextualizar a argumentação em defesa desse direito. E a expressão "interrupção da gestação" foi usada para nomear o processo de abortamento, também no contexto argumentativo que advoga o direito de decidir pelo aborto.

Há exatos dois anos, a liminar que autorizava mulheres grávidas de fetos anencefálicos a
interromper a gestação foi cassada pela mais importante corte do país. Durante quatro
meses, sob a proteção da liminar, dezenas de mulheres interromperam legalmente a
gestação, sem necessitar recorrer a uma autorização judicial. Esse foi um curto inter-
valo de tempo em que o Estado reconheceu que a decisão pela interrupção ou não da
gestação era matéria de ética privada - as mulheres e as equipes de saúde estavam livres
e protegidas para tomar a melhor decisão. A história de algumas dessas mulheres foi
apresentada no documentário “Quem são elas?", recentemente lançado em Brasília.

$\mathrm{Na}$ narrativa sobre a história de Severina, as expressões "procedimento médico" para nomear a interrupção da gestação e "filho natimorto", para referir-se ao concepto, somaram-se para marcar a posição moral de defesa da primazia da vida da gestante sobre a vida do feto que não é viável: “[...] Severina conseguiu um alvará judicial que autorizou o procedimento médico. $\mathrm{O}$ feto já nasceu morto e ela não pode ir ao enterro. $\mathrm{O}$ único registro do filho natimorto foi o atestado de óbito"

A construção gramatical "filho que não tem chance de sobreviver" também foi acrescentada para enfatizar a inexistência de vida a ser protegida nos fetos anencefálicos. 
Sem a decisão do Supremo favorável à interrupção da gestação nesses casos, hoje, as mulheres necessitam da solidariedade de seus médicos, mas são mulheres que experimentam a dor moral de um ato ilegal. Elas descrevem essa experiência - de manter a gestação de um filho que não tem chances de sobreviver - como um ato de tortura do Estado contra elas.

Sobre os usos da retórica no artigo "Anencefalia: dois anos de espera"

Os recursos estratégicos descrição vívida, narrativa e retórica de argumento foram identificados na análise retórica do artigo e são apresentados a seguir.

\section{Descrição Vívida}

A estratégia de elaborar um relato rico em detalhes contextuais foi usada na retórica de Débora Diniz para descrever o episódio de cassação da liminar do Ministro Marco Aurélio Mello. Essa construção retórica foi organizada de modo a sustentar a sua tese de que o Estado brasileiro não é considerado em sua laicidade.

A liminar foi cassada em 20 de outubro de 2004. O julgamento foi uma sessão tensa, em que argumentos religiosos e acusações morais se misturaram a teses jurídicas pouco fundamentadas na razão pública.

\section{Narrativa}

O recurso estratégico narrativa foi usado na composição do relato que construiu o favorecimento dado às mulheres que conseguiram realizar a interrupção da gestação no período em que vigorou a liminar.

Há exatos dois anos, a liminar que autorizava mulheres grávidas de fetos anencefálicos a interromper a gestação foi cassada pela mais importante corte do país. Durante quatro meses, sob a proteção da liminar, dezenas de mulheres interromperam legalmente a gestação, sem necessitar recorrer a uma autorização judicial.

A narrativa também foi utilizada para construir descrições sobre o caso de Severina, gestante de feto anencefálico. As informações da biografia desta gestante foram apresentadas seguindo uma sequência de acontecimentos, e a construção retórica enfatizou aspectos emocionais da perda do feto inviável. 
No mesmo dia que a liminar foi cassada, Severina, uma agricultora analfabeta de Chã Grande, em Pernambuco, estava internada em um hospital público do Recife para interromper a gestação. A força do Estado foi implacável com Severina: de um pré-operatório para interromper a gestação, Severina voltou para casa, onde durante três meses procurou reverter a decisão em cortes locais de justiça. Aos 7 meses de gravidez, Severina conseguiu um alvará judicial que autorizou o procedimento médico. $\mathrm{O}$ feto já nasceu morto e ela não pode ir ao enterro. $\mathrm{O}$ único registro do filho natimorto foi o atestado de óbito.

\section{Retórica de argumento}

A retórica de argumento foi utilizada para construir afirmações que objetivaram tornar irrefutáveis as sentenças de defesa de um Estado laico. A desconsideração de questões metafísicas, como saber quando se inicia a vida, qualificadas como posição de fé, caracterizou o movimento persuasivo de convencimento da irrelevância dessa questão para o tratamento do tema do aborto.

Para os ministros do Supremo, concepções de bem se subordinam a princípios de justiça, o que significa que controvérsias religiosas sobre o início ou o sentido da vida não serão solucionados pela corte. E, talvez, não devam ser resolvidas por nenhuma instituição da estrutura básica de um Estado laico. Os fundamentos da moralidade do aborto são como atos de fé: professam-se ou não.

O recurso listas e contrastes foi combinado com a retórica de argumento para enumerar e somar ao caso de Severina outras histórias de mulheres que gestaram fetos anencefálicos.

A história de Severina não deve ser entendida apenas como um exemplo de uma infeliz coincidência. Severina representa as mulheres brasileiras que dependem da legalidade para serem senhoras de sua própria história. Mulheres como Dulcinéia, Michelle, Érica e Camila, que também viveram o drama de gerar filhos sem cérebro.

A retórica de argumento também foi combinada com a narrativa para construir o apelo à solidariedade para com as mulheres gestantes de fetos anencefálicos. A organização retórica visou suplantar a dúvida acerca da inviabilidade do feto e atestar a inexistência de vida humana a ser protegida ou valorizada, nos casos desses fetos: 
Sem a decisão do Supremo favorável à interrupção da gestação nesses casos, hoje, as mulheres necessitam da solidariedade de seus médicos, mas são mulheres que experimentam a dor moral de um ato ilegal. Elas descrevem essa experiência - de manter a gestação de um filho que não tem chances de sobreviver - como um ato de tortura do Estado contra elas. O diagnóstico de anencefalia é implacável: não há cura, tratamento ou qualquer forma de reverter o óbito precoce do futuro filho. O Estado as obriga ao dever da gestação apenas para enterrar o filho natimorto?

A insistência na força retórica persuasiva contribuiu para afirmar a necessidade de se conceber a laicidade do Estado brasileiro e apresentar o sofrimento das gestantes de anencéfalos como fato real, cuja veracidade foi atestada pela descrição, na forma de um documentário etnográfico sobre a história de algumas dessas gestantes, que Débora Diniz relatou ter apresentado aos Ministros do STF.

Há dois anos se espera pelo julgamento do mérito da ação. Essa será uma oportunidade para devolver o tema da anencefalia para o único espaço moral legítimo: essa é matéria de ética privada e como tal não deve ser disciplinada pela força do Estado. Os ministros do Supremo foram apresentados às histórias de Severina, Dulcinéia, Michele, Érica e Camila. Resta saber se o mundo real os inspirará por um caminho diferente da abstração do julgamento que cassou a liminar.

\section{Carlos Alberto Di Franco: porta-voz da posição "pró-vida"}

Os artigos "Aborto e democracia”, publicado em 2004, e "Brasileiro é contra o aborto", de 2006, são as duas matérias jornalísticas produzidas por Di Franco analisadas para a descrição dos argumentos contra a liminar do Ministro Marco Aurélio Mello.

\section{$O$ artigo "Aborto e democracia"}

Como reação contrária à liminar, o jornalista Carlos Alberto Di Franco publicou um artigo, no jornal O Estado de S. Paulo, em agosto de 2004, cujo argumento centrou-se na defesa do direito do feto à vida. O texto, de uma página e meia, foi escrito numa linguagem jornalística e composto pela retórica epidêitica. Nele, o jornalista, condenou moralmente os defensores do direito ao aborto nos casos de anencefalia do feto.

A intertextualidade do artigo de Di Franco foi composta pelos dados estatísticos que ele empilhou na sua argumentação e por trechos de uma carta 
escrita por uma gestante de feto anencefálico cujo relato confluiu com a sua argumentação. O endereçamento foi realizado, reiteradamente, ao leitor do jornal no qual o artigo foi publicado.

\section{Sobre os usos dos dícticos no artigo "Aborto e democracia"}

A análise dos dícticos no artigo de Di Franco seguiu os mesmo passos dos outros documentos analisados nesta pesquisa.

Os dícticos de tempo foram usados para situar, temporalmente, o acontecimento da liminar do Ministro Marco Aurélio Mello e mencionar o tratamento da anencefalia em outros países. Os dícticos de lugar foram utilizados com a finalidade de localizar a ação que autorizou o aborto em casos de gestação de fetos anencefálicos e enunciar as estatísticas de ocorrência de anencefalia a nível nacional; anunciar locais onde o tratamento da anencefalia poderia servir de exemplo para o Brasil. Os dícticos do tipo social foram usados para nomear e distinguir o papel social do autor/relator da liminar; indicar o endereçamento do discurso; distinguir e enunciar a responsabilidade do Ministério da Saúde em relação à anencefalia. Os dícticos de discurso foram empregados para enunciar o relato de uma gestante de anencéfalo, que optou por levar a termo a gestação, e indicar o contexto de produção do depoimento da gestante de anencéfalo.

Quanto aos argumentos de autoridade, o Ministério da Saúde foi usado para mencionar estatística de morte de fetos anencefálicos. Trazer o Ministério como possível aliado constituiu uma estratégia de afirmação da responsabilidade do Estado sobre a gestão das vidas dos cidadãos que posicionou moralmente Di Franco como defensor do estatuto do feto como pessoa. O argumento "alguns autores" foi empregado para elaborar afirmações sobre um suposto tratamento para a anencefalia. A construção "médicos e especialistas da área" foi usada com a finalidade de contra-argumentar sobre os efeitos físicos e psíquicos da gestante de fetos anencefálicos. $\mathrm{O}$ "depoimento de uma mãe" foi usado como argumento de autoridade para afirmar que o sofrimento da gestante não justifica o aborto, e o jornal $O$ Globo foi usado para atestar que o depoimento da gestante havia sido publicado por um veículo de comunicação e empilhar o argumento da ilegitimidade do motivo pelo qual se requereu o aborto nos casos de anencefalia do feto. 
Sobre os usos dos repertórios interpretativos no artigo "Aborto e democracia"

A análise dos repertórios interpretativos seguiu o mesmo modelo interpretativo adotado para os demais documentos analisados. $\mathrm{O}$ enfoque aqui continua sendo os repertórios associados à interrupção da gestação, gestante e concepto. O quadro a seguir ilustra a sistematização dos usos dos repertórios interpretativos no artigo de Di Franco.

Di Franco fez referência ao processo de abortamento, denominando-o "interrupção voluntária da gravidez". Numa retórica epidêitica, ele centrou seus argumentos na avaliação e descrição da liminar, utilizando o termo "interrupção da gestação" para fazer menção ao contexto do processo jurídico em que se encontrava o despacho do Ministro Marco Aurélio Mello, passando em seguida a usar a nomeação "aborto", para referir-se aos seus posicionamentos diante do tema:

Recente liminar concedida pelo ministro Marco Aurélio Mello, do Supremo Tribunal Federal (STF), autorizando a interrupção da gestação de fetos com anencefalia, reacendeu o debate sobre a legalização do aborto no Brasil.

As expressões "gestante" e "mãe" se intercalaram como repertórios associados à portadora do feto anencefálico e foram organizadas na retórica de forma a evidenciar o sentimento maternal em supremacia ao sofrimento de gestar um feto inviável:

No tocante ao inegável sofrimento vivido pela gestante, reproduzo o depoimento de uma mãe que, não obstante a dor provocada pela morte do feto anencefálico, justificou a sua decisão de levar a gravidez até o fim.

Di Franco fez um uso retórico do termo "aborto" para refutar o argumento dos seus dissidentes que afirmou o sofrimento da gestante. A premissa moral da ladeira escorregadia (Diniz, 2004) foi defendida pelo jornalista que usou metáforas para dar sentido de horror e extermínio ao uso do termo "aborto". O emprego do apelo emotivo associado ao termo "aborto" emprestou força persuasiva ao discurso de Di Franco, que fez menção a eutanásia como estratégia argumentativa de comparação, tornando sua descrição mais efetiva e dando-lhe uma dimensão extrema. 
O aborto, estou certo, é o primeiro elo da imensa cadeia da violência e da cultura da morte. Após a implantação do aborto descendente (eliminação do feto), virão inúmeras manifestações do aborto ascendente (supressão da vida do doente) - a eutanásia já está sendo incorporada ao sistema legal de países europeus -, do idoso e, quem sabe, de todos os que constituem as classes passivas e indesejadas da sociedade.

Ao final de seu discurso o termo "feto" foi substituído por "criança não nascida”. Tal nomeação marcou a posição moral do jornalista, que organizou seu discurso em torno da metáfora da ladeira escorregadia:

Não se compreende de que modo obteremos uma sociedade mais justa e digna para seres humanos (os adultos) por meio da organização da morte de outros (as crianças não nascidas). Há um elo indissolúvel entre a prática do aborto, o massacre do Carandiru, a chacina da Candelária e outras agressões à vida: o ser humano é encarado como objeto descartável.

Sobre os usos da retórica no artigo "Aborto e democracia"

Imprecisão sistemática, relatos empiricistas e retórica de argumento foram os recursos estratégicos identificados na análise retórica do artigo de Di Franco e são apresentados a seguir.

\section{Imprecisão Sistemática}

Como referimos anteriormente, Di Franco fez um uso retórico do termo "aborto" para refutar o argumento que afirmou o sofrimento da gestante. Para tanto, utilizou contra-argumentos que generalizaram, por meio de construções imprecisas e vagas, a tese aceita pelos favoráveis à liminar (de que a interrupção da gestação nos casos de anencefalia não tipifica aborto), transladando o argumento de seus opositores para outro domínio de problemas sociais, usando metáforas e analogias como contra-argumentos que são organizados para fazer crer que são verídicos e baseados na sua leitura crítica da realidade:

O aborto, estou certo, é o primeiro elo da imensa cadeia da violência e da cultura da morte. Após a implantação do aborto descendente (eliminação do feto), virão inúmeras manifestações do aborto ascendente (supressão da vida do doente) - a eutanásia já está sendo incorporada ao sistema legal de países europeus -, do idoso e, quem sabe, de todos os que constituem as classes passivas e indesejadas da sociedade. 
A imprecisão sistemática foi combinada com a formulação de casos extremos como recurso argumentativo que direcionou a interpretação do discurso do jornalista para o extremo da dimensão relevante sobre democracia, segundo a sua ótica. Esse recurso estratégico foi agrupado com outros argumentos que rompiam e derrubavam as teses favoráveis à liminar, funcionando como retóricas que descreviam a realidade e organizavam o argumento em torno do uso de metáforas fatalistas. Esta estratégia caracterizou um discurso ironizador, dedicado a solapar as versões opostas, sobre a legitimidade dos argumentos favoráveis à liminar:

A eventual aprovação do aborto de fetos com anencefalia abre um perigoso precedente antidemocrático. Trata-se, na verdade, de um passo na estratégia dos que defendem o aborto amplo e irrestrito. Outros virão, não duvidemos. A democracia é, sem dúvida, o regime que mais genuinamente respeita a dignidade da pessoa humana. Qualquer construção democrática, autêntica, e não apenas de fachada, reclama os alicerces dos valores éticos fundamentais. Por isso, não obstante a força do marketing emocional que apoia as campanhas abortistas, é preocupante o veneno antidemocrático que está no fundo dos slogans abortistas. Não se compreende de que modo obteremos uma sociedade mais justa e digna para seres humanos (os adultos) por meio da organização da morte de outros (as crianças não nascidas). Há um elo indissolúvel entre a prática do aborto, o massacre do Carandiru, a chacina da Candelária e outras agressões à vida: o ser humano é encarado como objeto descartável.

\section{Relatos empiricistas}

Di Franco organizou seu discurso de forma a seguir uma sequência lógica, apresentando um relato empirista e empilhando informações estatísticas no seu argumento. Essa estratégia retórica teve por efeito construir versões do fato social (anencefalia) como se este fosse sólido e factual. O objetivo retórico de demonstrar a não pertinência dos argumentos dos seus opositores foi atingido por meio da organização do discurso em torno da argumentação pelo exemplo, cuja estratégia foi pressupor a existência de uma regularidade da ocorrência da anencefalia para generalizar as formas como ela ocorreria em outras regiões do mundo. Tal retórica foi caracterizada por um caráter ironizador, pois Di Franco fez afirmações que contradiziam a literatura médica sobre anencefalia que sustentou a determinação da liminar: a de que a anencefalia não tem cura e que só há prevenção se o acido fólico for ministrado pelo menos três meses antes da gestação, e não durante, como 
afirma Di Franco. O jornalista quis fazer crer, pela força persuasiva de sua versão sobre anencefalia, que a patologia tem cura, e construiu esse argumento como fato real:

[...] a anencefalia é uma malformação grave caracterizada por ausência dos ossos do crânio, exceto pelo osso frontal, e inexistência dos hemisférios cerebrais. O feto costuma ter uma sobrevida extrauterina curta. A incidência é de 0,1 a 0,7 caso em cada mil nascidos, com predomínio do sexo feminino. Segundo dados do Ministério da Saúde, ocorrem no Brasil, em média, 616 mortes por ano. Atualmente, em países do norte da Europa é preconizado o uso do ácido fólico no primeiro trimestre da gestação para prevenir a anencefalia. O resultado, notável, indica uma redução de um terço na incidência da patologia. Alguns autores afirmam que o não-aparecimento de defeitos no tubo neural chega a atingir $85 \%$. Trata-se, sem dúvida, de uma experiência que deveria ser valorizada pelo nosso Ministério da Saúde.

\section{Retórica de Argumento}

Di Franco lançou mão de técnicas argumentativas que organizaram a retórica de forma a estabelecer uma estrutura factual para a realidade que ele descreveu, apresentando uma relação de causa e efeito entre a liminar, que tratava exclusivamente da anencefalia, e o debate mais amplo sobre o aborto. Para estabelecer a ruptura com a tese apresentada na liminar, o jornalista refutou o argumento do seu opositor, utilizando o discurso ironizador para desacreditar a versão dos fatos apresentados na liminar pelo Ministro Marco Aurélio Mello:

A decisão do ministro, a quem talvez tenham chegado apenas dados médicos parciais e, certamente, influenciado pela força de compreensíveis argumentos emocionais (o presumível sofrimento da gestante), será em breve submetida à discussão do plenário do STF.

Ao longo do seu artigo a retórica utilizada por Di Franco situou o tema do aborto numa arena política e apresentou os argumentos dos seus opositores na controvérsia para assim derrubá-los. Ao sustentar o caráter inverossímil das descrições dos opositores, o jornalista fez um movimento retórico de força persuasiva para defender que as versões dos fatos dos seus oponentes eram falsas e ingênuas. A ruptura e oposição às teses favoráveis à liminar foram fortalecidas pela combinação da oratória ofensiva, desqualificando e 
deslegitimando os argumentos que ele refutou, com a argumentação organizada retoricamente. A estrutura argumentativa apresentada pelo jornalista foi semelhante à estrutura da lógica formal: a sua oratória recorreu a argumentos de autoridade "médicos e especialistas" para atestar a validade do seu raciocínio. Argumentos baseados na versão de realidade descrita pelo jornalista foram utilizados para transladar a interpretação sobre o argumento de risco da gestante para o risco do processo de abortamento em si, e a oratória ofensiva foi também utilizada para oferecer descrições alternativas aos argumentos que defenderam a eficiência do diagnóstico da anencefalia por ecografia. A organização retórica do discurso do jornalista usou diferentes construções linguísticas para refutar o argumento de seus opositores e descrever de forma ofensiva a gestação de um anencéfalo. A normalização foi o recurso discursivo usado pelo jornalista para construir a factualidade do seu relato, atribuindo a categoria "normal" para a gestação de anencéfalos como estratégia de refutação para os argumentos que defenderam tal gestação como de risco para a gestante. A retórica foi organizada de forma a persuadir seus interlocutores a criarem uma imagem do anencéfalo similar à de fetos saudáveis. Os trechos abaixo ilustram esses usos retóricos.

Os argumentos favoráveis à liminar do ministro Marco Aurélio Mello se apoiam em supostos riscos físicos e psíquicos para a gestante. Pelo que pude apurar com médicos e especialistas da área, o argumento é falso. A gestação de um feto anencéfalo é absolutamente normal. Muito mais graves e reais são os riscos que envolvem a prática do aborto. Além disso, embora remotas, existem possibilidades de erros de diagnóstico. Por isso, a autorização prévia, genérica, seria, caro leitor, uma irresponsabilidade ética. Os argumentos esgrimidos em defesa dessas ações, alguns cruéis, outros carregados de eufemismos emocionais, não conseguem ocultar o desrespeito ao primeiro direito humano fundamental, base da sociedade democrática: o direito à vida.

\section{O artigo "Brasileiro é contra o aborto"}

Em outubro de 2007, Carlos Alberto Di Franco escreveu outro artigo jornalístico, intitulado "Brasileiro é contra o aborto", também publicado no jornal O Estado de S. Paulo. Nesse artigo, o jornalista retomou e repetiu os mesmos argumentos que defendeu no artigo "Aborto e democracia". Di Franco reproduziu as mesmas construções gramaticais e os mesmos usos retóricos; até mesmo a estrutura argumentativa foi a mesma. Ele iniciou o 
artigo apresentando dados de uma pesquisa, o que compôs os elementos peculiares desse artigo como novos argumentos de autoridade, e em seguida retomou a descrição do depoimento da gestante que ele narrou no artigo anterior e seguiu com a mesma retórica.

Sobre os usos dos dícticos do discurso como argumentos de autoridade no artigo "Brasileiro é contra o aborto"

A utilização dos dícticos nesse artigo de Di Franco se constituiu de forma muito semelhante ao artigo anterior. Por isso, nos detemos, exclusivamente, nos usos dos dícticos como argumentos de autoridade, uma vez que esses usos foram distintos em relação ao artigo analisado anteriormente.

$\mathrm{O}$ argumento de autoridade "Pesquisa Data Folha" foi usado com a finalidade de sustentar a tese de que o povo brasileiro rejeitaria o aborto induzido. Esse elemento foi o que o jornalista trouxe de contemporâneo para marcar a sua retórica epidêitica. $\mathrm{O}$ "depoimento de uma mãe" se repetiu como argumento de autoridade para defender a posição que o sofrimento da gestante não justifica o aborto. $\mathrm{O}$ mesmo acontece com o argumento de autoridade "Jornal O Globo" usado para atestar que o depoimento havia sido veiculado por um veículo de comunicação e empilhar o argumento da ilegitimidade do motivo pelo qual se solicitou a legalização do aborto nos casos de anencefalia.

Sobre os usos dos repertórios interpretativos e da retórica no artigo "Brasileiro é contra o aborto"

Como mencionamos, os usos dos repertórios interpretativos se repetem nos dois artigos analisados. Em vista disso, analisamos aqui apenas os repertórios que tiveram um emprego distinto do artigo anterior. Tendo em vista que os usos retóricos também se repetiram, interpretamos, juntamente com a análise dos repertórios, as estratégicas retóricas utilizadas no artigo.

O emprego do termo "aborto" para referir-se à interrupção da gestação foi relacionado ao sentido de criminalidade e imoralidade, com expressa condenação do ato pelo jornalista. Ele utilizou dados de pesquisa para sustentar a legitimidade do seu argumento e desconstruir as versões dos seus dissidentes, apoiadores do direito à escolha, recorrendo a generalizações e formulações extremas: 
Pesquisa Datafolha divulgada no domingo, dia 7, constatou um expressivo aumento da rejeição ao aborto no Brasil. Para $87 \%$ dos entrevistados, fazer um aborto é algo moralmente errado. A maioria declara que daria apoio a um filho ou filha no caso de uma gravidez na adolescência, e rejeita a prática do aborto.

A formulação de casos extremos com o uso retórico do termo "aborto" foi organizada de modo a tornar o relato do jornalista mais expressivo, direcionando ao extremo as dimensões do seu julgamento acerca da moralidade do abortamento induzido e a sua defesa pelo direito à vida do feto.

O brasileiro é contra o aborto. Não se trata apenas de uma opinião, mas de um fato medido em pesquisa de opinião. Por isso o governo precisa ir devagar com o andor. A legalização do aborto seria, hoje e agora, uma ação nitidamente antidemocrática. Ademais, existe a questão dos princípios. A democracia é o regime que mais genuinamente respeita a dignidade da pessoa humana. Qualquer construção democrática, autêntica e não apenas de fachada, reclama os alicerces dos valores éticos fundamentais.

\section{Considerações finais}

Este artigo analisou os argumentos usados retoricamente pelo porta-voz da posição "pró-escolha", representada pela feminista Débora Diniz, e da posição “pró-vida”, concebida pelo jornalista Di Franco. Em sua retórica, Débora Diniz posicionou moralmente a premissa de defesa da vida da gestante e do seu direito de decidir pela interrupção da gestação. Ela argumentou em defesa da pluralidade moral, refutou as concepções morais que consideram a existência de vida humana a ser protegida desde a fecundação e refutou a consideração de questões metafísicas, como saber quando se inicia a vida, qualificando-as como posição de fé.

$\mathrm{O}$ apelo à solidariedade para com as gestantes de fetos anencefálicos teve a função retórica de enfatizar a valorização da vida da mulher e vitimá-la frente ao sofrimento de gestar um feto inviável. A postura política feminista, de defesa do direito de escolha, e a afirmação da anteposição da vida da gestante em relação à vida do feto, foram as principais sentenças morais argumentadas por Débora Diniz. Na sua retórica, a vida da gestante teve valor intrínseco por ter sido investida com uma biografia, em contraposição à vida do feto, que não teria chance de se tornar pessoa.

Di Franco estabeleceu uma estratégia de afirmação da responsabilidade do Estado sobre a gestão da vida dos cidadãos, posicionando-se moralmente 
como defensor do estatuto do feto como pessoa. Invocar o poder do governo para garantir a sobrevivência dos fetos anencefálicos conformou o argumento de que o estado tem o dever de legislar sobre quem merece viver e quando a vida humana se inicia, também fez entrever a estratégia de política da vida pautada em premissas religiosas de defesa do direito do feto à vida por ser esta um "presente" de ordem divina.

Conclui-se que a redução da complexidade da questão do aborto, transformada em um problema simples, sugerindo respostas esquemáticas de base binária, cuja dimensão de racionalidade cede espaço à transcendência, obstaculariza a construção de espaços múltiplos de discussão. Questões sobre quando a vida se inicia, qual o estatuto do feto/embrião, ou se é moralmente correto abortar, tem respostas particulares, íntimas, que dizem respeito a crenças e situações de vida individuais. Portanto, a diversidade ética e moral devem ser respeitadas, e o debate deve permear o campo da pluralidade de crenças.

\section{Referências bibliográficas}

BILLIG, Michael. 1991. Ideology and opinions: studies in rhetorical psychology. London: Sage.

DINIZ, Débora. 2004. “Antecipação terapêutica de parto: uma releitura bioética do aborto por anomalia fetal do Brasil". In:. DINIZ, Débora; RIBEIRO, Diaulas Costa (eds.). Aborto por anomalia fetal. Brasília: Letras Livres.

DINIZ, Débora \& VÉLEZ, Ana Cristina G. 2008. “Aborto na Suprema Corte: o caso da anencefalia no Brasil". Revista Estudos Femininos, v. 16, n. 2, p. 647-652.

DOMINGUES, Roberto C. 2008. "Entre normas e fatos, o direto de decidir: o debate sobre o aborto à luz dos princípios constitucionais". In: MAIA, Mônica Bara (org). Direito de decidir: múltiplos olhares sobre o aborto. Belo Horizonte: Autêntica.

IÑIGUEZ, Lupicinio. 2004. "Os fundamentos da análise do discurso”. In: IÑIGEZ, Lupicinio (coord.). Manual de análise do discurso em ciências sociais. Petrópolis: Vozes.

LEACH, Joan. 2002. "Análise retórica”. In: BAUER, Martin W. \& GASKELL, George (eds.) Pesquisa qualitativa com texto, imagem e som: um manual prático. Trad. Pedrinho A. Guareschi. Petrópolis: Vozes. 
ORGANIZAÇÃO MUNDIAL DE SAÚDE (OMS). 2004. Abortamento seguro: orientação técnica e de políticas para os sistemas de saúde. Campinas: Cemicamp.

POTTER, Jonathan. 1996. La representación social de la realidad: discurso, retórica y construcción social. Barcelona: Paidós.

\& WETHERELL, Margaret. 1987. Discourse and social psychology. London: Sage.

SANEMATSU, Marisa. 2005. "Interrupção da gravidez em caso de anencefalia fetal: a cobertura da imprensa sobre a liminar do STF e suas repercussões". In: ADESSE, Leila (org.). A saúde sexual e reprodutiva da mulher no Brasil: diferentes visões no contexto do aborto. Porto Alegre: Metrópole.

SANTIAGO, Ricardo C. 2008. "Saúde da mulher e aborto". In: MAIA, Mônica Bara (org). Direito de decidir: múltiplos olhares sobre o aborto. Belo Horizonte: Autêntica.

SPINK, Mary Jane P. (org.). 2000. Práticas discursivas e produção de sentidos no cotidiano: aproximações teóricas e metodológicas. 2a ed. São Paulo: Cortez.

\section{Resumo}

Este artigo apresenta uma análise retórica das posições "pró-escolha" e "pró-vida" no debate sobre o aborto de fetos anencefálicos. A feminista Débora Diniz é considerada como porta-voz da posição "pró-escolha" por ter sido a principal articuladora política da ação judicial que suscitou na liminar que autorizou, em 2004, a antecipação terapêutica do parto de fetos anencefálicos. Carlos Alberto Di Franco é o porta-voz da posição "pró-vida", principal representante dos interesses da hierarquia da Igreja Católica. No discurso de Débora Diniz, o apelo à solidariedade para com as gestantes de fetos anencefálicos teve a função retórica de enfatizar a valorização da vida da mulher e vitimá-la diante do sofrimento de gestar um feto inviável. Di Franco estabeleceu uma estratégia de afirmação da responsabilidade do Estado sobre a gestão da vida dos cidadãos, posicionando-se moralmente como defensor do estatuto do feto como pessoa.

Palavras-chave: aborto; anencefalia; retórica; mídia.

\section{Abstract}

This article presents a rhetorical analysis of the "pro-choice" and "pro-life" stances in the debate over abortion of anencephalic fetuses. Feminist Debora Diniz is regarded as a pro-choice" spokeswoman. She was the main political organizer of the lawsuit filed by 
the National Confederation of Health Workers resulting in the 2004 provisional court decision authorizing therapeutic advance delivery of anencephalic fetuses. Carlos Alberto Di Franco is the "pro-life" spokesman - the main representative of the interests of the Roman Catholic hierarchy. In Mrs. Diniz's discourse, the appeal for solidarity with the mothers of anencephalic fetuses played the rhetorical role of emphasizing the value of women's lives and make them a victim of the suffering of carrying unviable fetuses. Mr. Di Franco established a strategy of affirming the responsibility of the State in managing citizens's lives, positioning himself morally as the advocate of the status of the fetus as a person. Key words: abortion; anencephaly; rhetoric; media.

Recebido em junho de 2011.

Aprovado em agosto de 2011. 